\title{
Study on Fresh Agricultural Products Supply Chain Structure and Status Monitoring
}

\author{
Xixi Zhang ${ }^{*}$, Hui Hu, Hezhen Ma and Xing Fu \\ School of Automobiles, Chang'an University, Xi'an 710064, China \\ ${ }^{*}$ Corresponding author
}

\begin{abstract}
Many fresh agricultural products (FAP) cannot achieve "smooth flow of goods" and "make the best value". FAP are perishable items and difficult to store and transport for a long time. Therefore, it is particularly necessary to study the structure of FAP supply chain. In this paper, firstly, it introduced the features of FAP supply chain and analyzed the existing types and structural characteristics of FAP supply chains. Secondly, taking the case of Shaanxi Province, this paper took advantage of principal component analysis (PCA) and cluster analysis to study the FAP supply chain of $\mathbf{1 0}$ cities. The results show that Xi'an belongs to consumer-oriented logistics city, it should mainly develop the logistics supply chain whose core is the third-party logistics or supermarket chains. At the same time, develop the logistics supply chain which is dominated by production and processing enterprises or wholesale markets as supplement. Tongchuan is an agricultural production-oriented logistics city, it should construct the supply chain that focus on production and processing enterprises and wholesale markets. Others are defined as logistics eclectic cities, they should focus on the development of agricultural production and processing enterprises according to different products in different cities. Finally, a environment configuration and platform of fresh agricultural products supply chain status monitoring was built based on the network of things to obtain the real-time information of products. The conclusions have certain significance to the selection of FAP supply chain in Shaanxi Province.
\end{abstract}

Keywords-fresh agricultural products; supply chain structure; principal component analysis; cluster analysis

\section{INTRODUCTION}

Under the trend of economic globalization, imports of foreign FAP make our agricultural products face a strong challenge and competition from developed countries. Even the Internet of Things technology is developing rapidly, FAP supply chain still have a variety of risks because of the imperfect logistics and frequent emergencies and other reasons. In this case, analyzing FAP supply chain and selecting the appropriate supply chain structure will help companies recognize the present situation and actively optimize the supply chain, and then achieve long-term competitive advantage in the fierce market competition.

\section{AnAlysis of Fresh Agricultural Products SUPPLY CHAIN}

\section{A. Fresh Agricultural Products Supply Chain: A Literature} Review

People cannot live without food, no matter in China or other countries. It is a question all over the world. FAP supply chain gets the international attention because of the food safety issues. Menard(2004) pointed out the trends that agricultural supply chain in Europe and America would work closely and strengthen the degree of integration in decades; Raynaud(2002)discussed the Relationship between governance structure and the quality of the signal of the agricultural supply chain by using the analytical framework of the New Institutional Economics; Omar Ahumada (2009) did a study on the production of agricultural crops and layout planning, focusing on quantitative models that have been carried out successfully, these quantitative models are classified based on relevant characteristics (such as the optimization methods, typical crop simulation and so on); Kung-JengWang (2011) studied optimal inventory strategy for products with timesensitive deteriorating rates in a multi-echelon supply chain. C.I.Costopoulou and M.A.Lambrou(2000)pointed out that establish agricultural logistics supply chain on the basis of virtual agricultural market system(VAM); Samir K.Srivastava (2007) proposed that agricultural logistics activities should be done based on the green supply chain; Terry Marsden(2000)believes that different agricultural produce supply chain should be chosen according to different characteristics of products, and then organize the logistics of agricultural activities. Wu Qingjun, Li Xue-gong (2007) set up a comprehensive evaluation system of agricultural product logistics including total 14 first indicators, 88 Second indicators, which reflected the whole picture of modern agricultural logistics; Wang Duchun, Chi Fengmin (2008) constructed the evaluation index system of modern circulation system of agricultural products from four areas: market system, market players, information systems, management mechanism. Zhang Hao, Sun Qingli, An Yufa (2009) set up a DEA model to estimate technical efficiency from investment point of view by using 2005 survey data from 50 major agricultural products wholesale market in China. Then compared technical efficiency of different types of agricultural products wholesale market that were classified by the standards of geographic area, business scope and ownership; Kang Biao (2011) completed the risk identification process through the analysis of risk factors in "Farming-Supermarket Docking". What is more, the author 
established a risk assessment model by using fuzzy theory and mathematical methods; Hou Yumei (2012) took case of Qinhuangdao, explained the advantages and disadvantages of the various supply chains through the analysis and comparison of the 5 supply chain; Yanbo (2014) used OWA operator to quantitatively evaluate these risk factors, and put forward measures and recommendations on agricultural supply chain risk management and control under the Internet of things.

\section{B. Classification of FAP Supply Chain Structure}

Generally speaking, the production and circulation of agricultural products consist of prenatal-information guide and product planning, middle- field management, and poststandardized processing, distribution, consumption, etc. FAP supply chain can be divided into the following structure forms:

1) Agricultural products wholesale market oriented mode

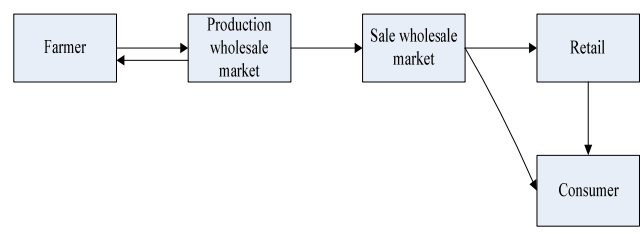

FIGURE I. AGRICULTURAL PRODUCTS WHOLESALE MARKET ORIENTED MODE

This mode is mainly connected through the wholesale market. The main features of this supply chain structure are: It is a short-lived transactions and long-term relationship is not established, each link cannot connect closely; participants scattered; no unified management; quality and safety cannot be guaranteed because of the difficult product regulation; each member of the supply chain intends to maximize the pursuit of their own interests, not to achieve the overall goal and maximum benefit of the supply chain.

2) Farmer's market oriented mode

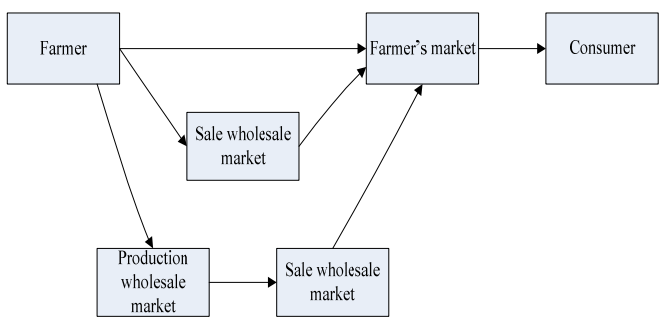

FIGURE II. FARMER'S MARKET ORIENTED MODE

This is one of the most traditional types. Most of the farmer's markets are located in urban suburbs, which have multi-product purchase channels. Farmer's market has the following characteristics: individual traders have superiority of operating costs and price; it is difficult for farmer's market to provide standard, healthy and fresh goods, then consumption safety cannot be guaranteed fundamentally.

3) Supermarket chains oriented mode

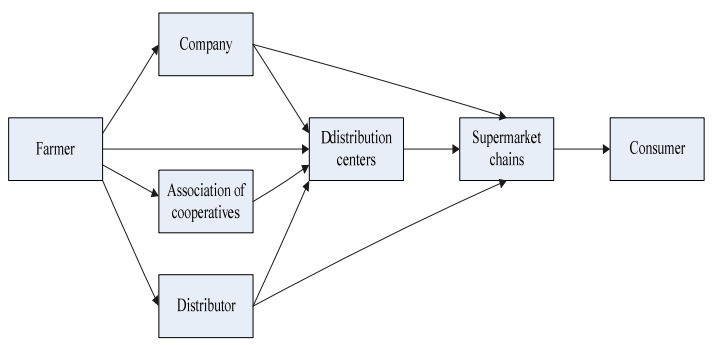

FIGURE III. SUPERMARKET CHAINS ORIENTED MODE

This supply chain has become the main mode of FAP. More and more consumers are willing to buy FAP in supermarket, where they can pick a good selection. Pollution-free, highnutrition has become the basic pursuit of consumers. Large supermarket typically has a large number of branches that exist difference in geographical presence, customer base, quality requirements, and sales species and so on. Generally the distribution centers can provide a stable, smooth sales channel to meet the needs in different branches. However, the supermarket has different scale and unstable quality of goods, what is more, the circulation of goods needs multi-level distributors, and the purchase price is generally higher. Compared with farmer's market and wholesale markets, it does not have a price advantage.

\section{4) Farming-supermarket docking}

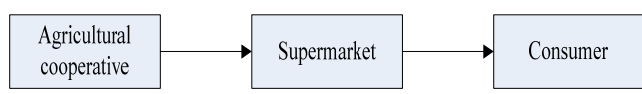

FIGURE IV. FARMING-SUPERMARKET DOCKING

It is a new type of FAP supply chain that connects farmer cooperatives and supermarkets directly. Farming-supermarket Docking can link the docking and sales effectively by reducing intermediate links to achieve market effectively guide the production and production directly to the market. In order to make it more suited to market needs and achieve value-added of agricultural and rural incomes, we can make adjustments in time, space, species and other aspects of the state of agricultural products, which will lay the foundation for a stable global economy.

\section{RESEARCH OF THE SUPPLy CHAIN STRUCTURE IN TYPICAL REgIONS OF SHAANXI PROVINCE}

Shaanxi is located in the northwest, which is one of the typical provinces that cross north and south. It is divided into 10 cities according to the administrative areas, due to the different climate and terrain, the FAP supply chains in 10cities are also different. Based on the analysis of the supply chain structure in the last chapter, PCA is used to evaluate the level of agricultural logistics and cluster analysis is used to divide 10 cites in different parts.

\section{A. Principal Component Analysis}

Principal component analysis is a statistical analysis method that can transform multiple indexes into a few principal components through dimensionality reduction technique. Most of the original indexes information can be reflected by these principal components, which are usually indicated as some 
certain linear combinations of original indexes. The following model can carry out a mathematical explanation to the Principal component analysis.

$$
\left\{\begin{array}{c}
F_{1}=u_{11} X_{1}+u_{12} X_{2}+\cdots+u_{1 p} X_{p} \\
F_{2}=u_{21} X_{1}+u_{22} X_{2}+\cdots+u_{2 p} X_{p} \\
\cdots \\
F_{p}=u_{p 1} X_{1}+u_{p 2} X_{2}+\cdots+u_{p p} X_{p}
\end{array}\right.
$$

Where, $x_{1}, x_{2}, \ldots, x_{p}$ are $\mathrm{P}$ original indexes, $F_{1}, F_{2}, \cdots$, $F_{p}$ indicate $\mathrm{P}$ comprehensive indexes which are independent of each other. Principal component analysis intends to use a comprehensive index $F_{1}$ to represent the $\mathrm{P}$ original indexes. In order to make $F_{1}$ the most representative in all linear combinations, its variance should be maximal, calling $F_{1}$ as the first principal component. If the first principal component contains insufficient original information, the second principal component F2 should be defined under the condition of Cov $\left(F_{1}, F_{2}\right)=0$. Similarly, the third principal component, the fourth principal component, ${ }^{\cdots}$, the $\mathrm{P}$ th principal component can be got. Principal component analysis can make the most of the variance of the original indexes focus on a few main components, and then achieve a comprehensive evaluation of the overall. Use the following formula to calculate the comprehensive evaluation scores:

$$
F=\sum_{i=1}^{m} \frac{\lambda_{i}}{\lambda_{1}+\lambda_{2}+\ldots+\lambda_{m}} \times F_{i}
$$

\section{1) Index selection and data collection}

In order to find the major factors affecting the level of agricultural logistics development in 10 cities and make preparation for cluster analysis. This paper selects 8 indexes (shown in Table 1) to make a research. Since 2014 data is not complete, so choose the relevant data in 2013 for analysis (shown in Table 2).

Infrastructure. Business volume of postal and telecommunication services, possession of vehicles in operation and length of highways included. These indexes mainly reflect that whether the hardware is in place or not;

Transport capacity. Transport plays an important role in the logistics process; including road freight traffic can measure the transport capacity effectively;

Supply factors. Gross output of agriculture, forestry, animal husbandry and fishery refers to the value of agricultural products around the city, which can reflect the supply capacity of agricultural products around the city;
Demand factors. Total retail sales of social consumer goods can reflect people's demand of various goods (fresh agricultural products included) exactly, as well as the spending power of people around the city;

Environmental factors. Agricultural supply chain needs to run under a large external environment, environmental factors are essential to any operation. Gross domestic product (GDP) and the number of usual residents are 2 effective indicators.

\begin{tabular}{|c|c|c|}
\hline Factors & $\begin{array}{l}\text { Specific } \\
\text { indexes }\end{array}$ & unit \\
\hline \multirow{3}{*}{ Infrastructure } & \begin{tabular}{l}
\multicolumn{1}{c}{ Business } \\
volume of postal and \\
telecommunication \\
services X1
\end{tabular} & Hundred million \\
\hline & \begin{tabular}{l}
\multicolumn{1}{c|}{ Possession of } \\
vehicles in operation \\
X2
\end{tabular} & Vehicle \\
\hline & \begin{tabular}{|c|} 
Length of \\
highways X3
\end{tabular} & Kilometers \\
\hline Transport capacity & Freight traffic X4 & Ten thousand ton \\
\hline Supply factors & 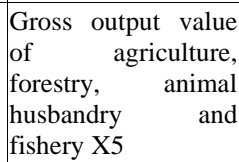 & Hundred million \\
\hline Demand factors & $\begin{array}{l}\text { Total retail sales } \\
\text { of consumer goods } \\
\text { X6 }\end{array}$ & Hundred million \\
\hline \multirow[b]{2}{*}{ Environmental factors } & GDP X7 & Hundred million \\
\hline & $\begin{array}{l}\text { Number of usual } \\
\text { residents X8 }\end{array}$ & Ten thousand person \\
\hline
\end{tabular}

TABLE I. EVALUATION INDEX SYSTEM OF LOGISTICS

Note: There is no Gross output value and consumption of agriculture in Statistical Yearbook, so Gross output value of agriculture, forestry, animal husbandry and fishery and Total retail sales of consumer goods instead.

\begin{tabular}{|c|c|c|c|c|c|c|c|c|}
\hline city & $X I$ & $X 2$ & X3 & $X 4$ & $X 5$ & $X 6$ & $X 7$ & $X 8$ \\
\hline Xi'an & 167.35 & $\begin{array}{l}1864 \\
12\end{array}$ & 13127 & $\begin{array}{l}4408 \\
2\end{array}$ & $\begin{array}{l}308.3 \\
6\end{array}$ & 2263.86 & 4366.1 & 855.29 \\
\hline $\begin{array}{c}\text { Tongch } \\
\text { uan }\end{array}$ & 7.23 & $\begin{array}{l}1042 \\
4\end{array}$ & 3707 & 3590 & 34.59 & 63.86 & 272.31 & 84.08 \\
\hline Baoji & 27.26 & $\begin{array}{l}2322 \\
8\end{array}$ & 15003 & 8933 & $\begin{array}{l}239.9 \\
7\end{array}$ & 412.83 & $\begin{array}{l}1374.3 \\
3\end{array}$ & 373.67 \\
\hline $\begin{array}{c}\text { Xianyan } \\
\mathrm{g}\end{array}$ & 33.07 & $\begin{array}{l}3257 \\
5\end{array}$ & 15403 & 7192 & $\begin{array}{l}465.3 \\
7\end{array}$ & 401.08 & $\begin{array}{l}1573.6 \\
8\end{array}$ & 492.86 \\
\hline Weinan & 35.05 & $\begin{array}{l}5534 \\
3\end{array}$ & 18073 & $\begin{array}{l}1232 \\
6\end{array}$ & 318 & 326.32 & $\begin{array}{l}1153.8 \\
0\end{array}$ & 532.10 \\
\hline $\begin{array}{c}\text { Hanzho } \\
\text { ng }\end{array}$ & 23.05 & $\begin{array}{l}2168 \\
25\end{array}$ & 17935 & 5637 & $\begin{array}{l}274.6 \\
6\end{array}$ & 216.05 & 754.57 & 341.84 \\
\hline
\end{tabular}

TABLE II. INDEXES DATA OF 10 CITIES IN SHAANXI 


\begin{tabular}{|c|l|l|l|l|l|l|l|l|}
\hline Ankang & 16.65 & $\begin{array}{l}1441 \\
6\end{array}$ & 22182 & 6820 & $\begin{array}{l}140.3 \\
9\end{array}$ & 151.49 & 496.91 & 263.36 \\
\hline $\begin{array}{c}\text { Shanglu } \\
\text { o }\end{array}$ & 10.94 & 6194 & 12988 & 639 & $\begin{array}{l}139.5 \\
5\end{array}$ & 107.28 & 423.31 & 234.19 \\
\hline Yan’an & 23.12 & $\begin{array}{l}3426 \\
3\end{array}$ & 16756 & 5711 & $\begin{array}{l}169.6 \\
9\end{array}$ & 151.74 & 1271.0 & 219.81 \\
\hline Yulin & 41.82 & $\begin{array}{l}7256 \\
3\end{array}$ & 25869 & 9595 & $\begin{array}{l}209.7 \\
2\end{array}$ & 279.22 & 2669.8 & 88 \\
\hline
\end{tabular}

\section{2) Data analysis}

In this paper, the SPSS20.0 is used to process the original data for principal component analysis. The first two principal components $\left(F_{1}\left(\lambda_{1}=5.843\right), F_{2}\left(\lambda_{2}=1.272\right)\right)$ whose eigenvalues are greater than 1 will be extracted and then analyzed. As shown in Table 3, the cumulative variance contribution of the first two principal components has reached $88.94 \%$. That is to say, the first two principal components to be extracted can reflect most information of original indexes. The score of the principal components and eigenvalues and the comprehensive evaluation scores are shown in table 4.

TABLE III. TOTAL VARIANCE EXPLAINED OF SPSS SOLVING PROCESS

\begin{tabular}{|c|c|c|c|c|c|c|}
\hline \multicolumn{6}{|c|}{ Total Variance Explained } \\
\hline \multirow{2}{*}{$\begin{array}{c}\text { Compon } \\
\text { ent }\end{array}$} & \multicolumn{5}{|c|}{ Initial eigenvalues } & \multicolumn{2}{c|}{$\begin{array}{c}\text { Extraction sums of squared } \\
\text { loading }\end{array}$} \\
\cline { 2 - 7 } & Total & $\begin{array}{c}\text { \% of } \\
\text { variance }\end{array}$ & $\begin{array}{c}\text { Cumulative } \\
\%\end{array}$ & Total & $\begin{array}{c}\text { \% of } \\
\text { varian-ce }\end{array}$ & $\begin{array}{c}\text { Cumula- } \\
\text { tive \% }\end{array}$ \\
\hline 1 & 5.843 & 73.039 & 73.039 & 5.843 & 73.039 & 73.039 \\
\hline 2 & 1.272 & 15.901 & 88.940 & 1.272 & 15.901 & 88.940 \\
\hline 3 & .707 & 8.836 & 97.777 & & & \\
\hline 4 & .128 & 1.599 & 99.376 & & & \\
\hline 5 & .031 & .390 & 99.766 & & & \\
\hline 6 & .011 & .141 & 99.907 & & & \\
\hline 7 & .007 & .092 & 99.998 & & & \\
\hline 8 & .000 & .002 & 100.000 & & & \\
\hline & Note: Extraction method: principal component analysis. & & \\
\hline
\end{tabular}

TABLE IV. SCORES OF THE PRINCIPAL COMPONENTS AND COMPREHENSIVE EVALUATION

\begin{tabular}{|l|c|c|c|}
\hline City & F1 & F2 & F \\
\hline Xi'an & 2.61504 & -0.97256 & 1.7533696 \\
\hline Tongchuan & -0.95138 & -2.14821 & -1.038221 \\
\hline Baoji & -0.13848 & -0.00471 & -0.101844 \\
\hline
\end{tabular}

\begin{tabular}{|c|c|c|c|}
\hline Xianyang & 0.16965 & 1.03267 & 0.2890717 \\
\hline Weinan & 0.16918 & 0.68281 & 0.232751 \\
\hline Hanzhong & -0.33951 & 0.53404 & -0.1623959 \\
\hline Ankang & -0.55328 & 0.44047 & -0.3334192 \\
\hline Shangluo & -0.7479 & -0.53277 & -0.6312102 \\
\hline Yan’an & -0.40678 & -0.09673 & -0.3124262 \\
\hline Yulin & 0.18345 & 1.065 & 0.3043185 \\
\hline
\end{tabular}

Draw the graph of logistics level in every city based on F:

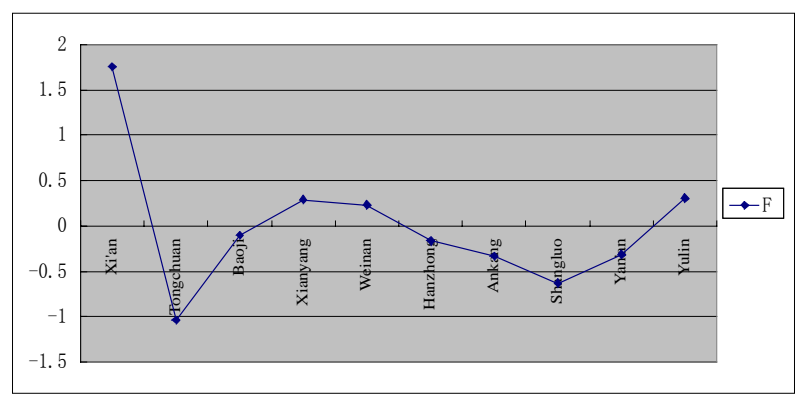

TABLE V. THE LEVEL OF LOGISTICS DEVELOPMENT IN 10 CITIES

According to the Figure 5, we can see that F scores of Xianyang, Weinan, Xi'an, Yulin are high, every high score has its own characteristics and reasons. Then we will make cluster analysis on the logistics development of each city.

\section{B. Cluster Analysis}

\section{1) Cluster analysis theory}

Cluster analysis is a statistical analysis method that divides subjects into a group of relatively homogeneous group, which is also known as statistical analysis or numerical taxonomy classification analysis. In this paper, hierarchical cluster analysis is adopted. The basic idea is to classify n samples (or index) as $\mathrm{n}$ classes and define the distance between each sample; In accordance with certain principles of the closest categories into a new category, get $n-1$ classification, and then calculate the distance between classes, and then find out the closest merged into a new category; Repeat the above steps until all the samples (or index) all combined into a class.

\section{2) Results analysis}

Using SPSS20.0 to select the principal component scores F1, F2 of 10 cities to make cluster analysis, and make the tree clustering results. Clustering results are shown in Figure6: 


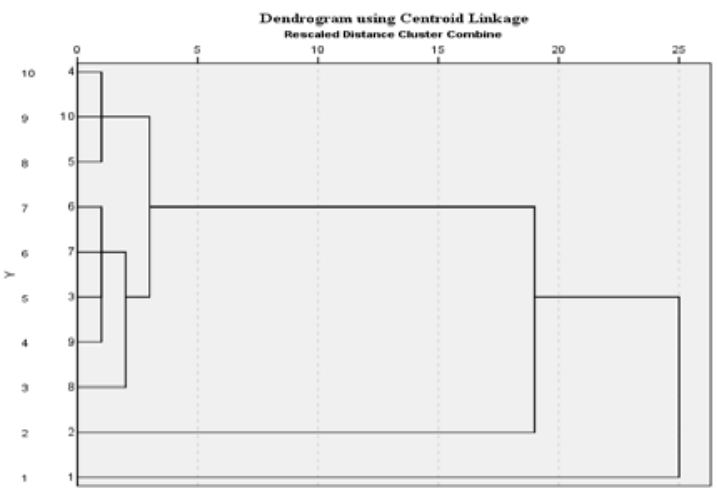

FIGURE V. RUNNING RESULTS OF CLUSTER ANALYSIS

10 cities of Shaanxi can be divided into 3 categories by cluster analysis as follows:

First class: Xi'an; High level of logistics development, large population and developed economy make Xi'an become the main city of FAP consumption, thus consumer-oriented logistics city. Xi'an, the capital of Shaanxi, is the political, economic and cultural center of Shaanxi province. Xi'an is the starting point of the Silk Road and the traffic fort of the northwest in China, railways and highways lead in all directions. A great number of colleges and advantages of institutions and policies in Xi'an makes this city develop significantly faster than the rest cities in Shaanxi. The large population means a large consumer market, so Xi'an belongs to the central city of consumer logistics. These entire make Xi'an get enough conditions to develop advanced logistics mode. It is necessary to mainly develop the logistics supply chain whose core is the third-party logistics or supermarket chains. At the same time, develop the logistics supply chain which is dominated by production and processing enterprises as well as wholesale markets as supplement.

Second class: Tongchuan; Tongchuan's lever of logistics is lower. It is located in the middle of Shaanxi, belongs to agricultural production-oriented logistics city. In recent years, agriculture, forestry and animal husbandry have got a rapid development, and the growth of the agricultural enterprises has made a great contribution to this. Tongchuan is an origin city of the fresh agricultural products logistics, which should mainly construct the supply chain that focus on production and processing enterprises and wholesale markets, and develop the logistics supply chain whose core is the third- party logistics as supplement.

Third class: Others; These cities belong to the logistics eclectic city. Among them, Xian yang, Weinan and Yulin have obvious advantages compared to other cities, especially Yulin. Yulin is located in the north of Shaanxi and close to the Yellow River, Ningxia, Gansu, Inner Mongolia and Yan'an, besides, it is rich in coal, oil, natural gas and salt, thus, Yulin is known as "Chinese Kuwait". Excellent location and a wealth of resources make Yulin's logistics and economic development go hand in hand, animal husbandry and fishery output value are also increasing year by year. The level of logistics development in other cities is lower; we should focus on the development of agricultural production and processing enterprises according to different products in different cities. We should build business, the wholesale market as the core of the supply chain. The logistics distribution in Yan'an is mainly on apple; in Hanzhong are pigs and tea and medicine; in Ankang are medicinal materials; in Shangluo is grain; in Baoji is livestock product.

\section{FAP SUPPLY CHAIN STATUS MONITORING BASED ON THE NETWORK OF THINGS}

Internet of things is a technology to connect objects, as well as collect and integrate data through RFID and various sensors. This paper adapts internet of things to collect terminal data (on fixed and moving monitoring nodes). Then it's uploaded to the cloud server through the network, subsequently processed and stored by the cloud server.

Thus, the method of environment configuration of supply chain logistics real-time status monitoring is illustrated as Fig 7.

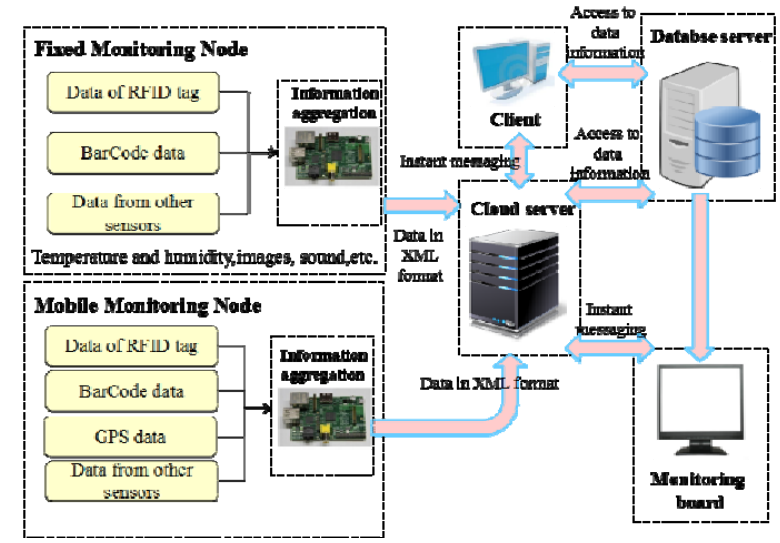

FIGURE VI. MONITORING ENVIRONMENT CONFIGURATION OF SUPPLY CHAIN LOGISTICS

Data collection terminal integrates information after the data collection process of fixed and moving nodes, then sends it to the cloud server in the format of XML. Data processing is brought about by the cloud server to get the second kind of information and it then saves it to the database. The monitoring board is used to achieve the visual presentation of supply chain logistics. The client ensures the basic functions of the system.

A software and hardware platform of supply chain logistics real-time status monitoring is then developed. Figure 8 shows connections among devices within the hardware platform, based on the monitoring environment configuration described in this paper. 


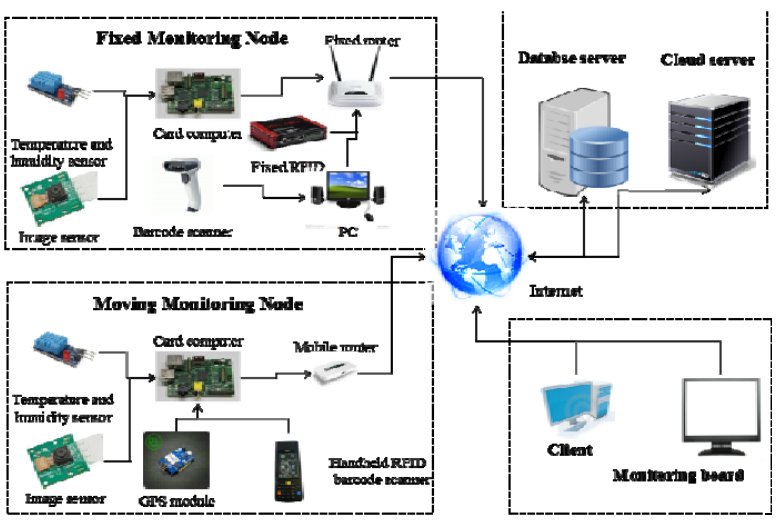

FIGURE VII. CONNECTIONS AMONG DEVICES WITHIN THE HARDWARE PLATFORM

Card computer is critical to monitoring environment configuration, it has three functions: data collection, data aggregation and information transmission, and the last one is achieved in format of XML. Data aggregated(including data of RFDI label, data from bar code scanning, GPS data, temperature and humidity data and image data, etc.) is sent to the cloud server by card computer through the network (3G / $4 \mathrm{G}$ / Wifi / cable) for further processing, then it is saved to the database by the cloud server. The client interacts with the database, save and modify data through the network,and the cloud server provides accesses to real-time information for it. The monitoring board receives real-time triggering signals from the cloud server through the network, then reads the information in the database to visually represent the real-time status of supply chain logistics process.

\section{CONCLUSIONS}

In this paper, we firstly made a qualitative analysis about the structural characteristics of the existing fresh products supply chain. Followed by the case of 10 cities in Shaanxi Province, we made a quantitative analysis about the choice of FAP supply chain structure by using principal component analysis and cluster analysis. Xi'an belongs to consumeroriented logistics city, and it should build the supply chain focus on supermarket chains and third-party logistics; such a low level of logistics development, Tongchuan should develop the supply chain focus on production and processing enterprises and wholesale market; other cities should develop different supply chain with different dominant agricultural products. Finally we developed the real-time status monitoring environment configuration and platform of supply chain to provide access to real-time information of FAP. The conclusions will not only provide a direction for the construction of FAP supply chain in Shaanxi province, but also provide an analysis method for the construction of FAP supply chain in other provinces. The future research can be extended to the simulation and optimization of FAP supply chain structure.

\section{ACKNOWLEDGMENT}

This research is supported by the China National Science and Technology Support Program (2014BAH23F01).

\section{REFERENCES}

[1] Bi Yuping, 2011.Study on Logistics and Supply-Chain Model of Fresh Agricultural Products in Shandong. Northwest A\&F University, Xianyang.

[2] C.I.Costopoulou, M.A.lambrou., 2000.An architecture of Virtual agricultural market system: The case of trading perishable agricultural products. Information Service \& Use, 127 (20):39-48.

[3] Donald J.Bowersox, David J.Closs., 2007.Supply Chain Logistics Management,1st edition. China Machine Press, Beijing.

[4] Dupuy C, Botta-Genoulaz V, Guinet A., 2005.Batch dispersion model to optimize traceability in food industry. Journal of Food Engineering, 70(3):333-338.

[5] Hou Yumei, Liu Lizhuo.,2012. Research on Supply Chain Mode of Fresh Agricultural Products in Hebei. Journal of Yanshan University, 28(1): 67-71.

[6] Jiang Kan, 2006.Analysis and Optimization of Agricultural Products Supply Chain. Coastal Enterprises and Science \& Technology, 30(1):5759.

[7] Li Xiaoling, Zhang Weina., 2010.Exploration of Development of Modern Logistics Mode in Wholesale Market of Traditional Agricultural Products. Logistics Technology, 28(5):25-27.

[8] Kang Biao, 2011.Research on Farming - Supermarket Docking's Risk Management. Beijing Jiaotong University, Beijing.

[9] Kung-JengWang, Y. S. Lin, JonasC. P. Yu., 2011. Optimizing inventory policy for products with time-sensitive deteriorating rates in a multiechelon supply chain. Int. J. Production Economics, 130 (78): 66-67.

[10] Mo Lianguang, 2011. A Study on Modern Agricultural Products Logistics Supply Chain Management Mode Based on IOT, 2nd International Conference on Digital Manufacturing \& Automation, Changsha.

[11] Ménard, Claude and Peter G Klein., 2004. Organizational Issues in the Agri-Food Sector: Toward a Comparative Approach. American Journal of Agricultural Economics, 86 (3): 102-113.

[12] Narasimhan R, Talluri S.,2009. Perspectives on risk management in supply chains. Journal of Operations Management, 27(2):114-118.

[13] Omar Ahumada, J. Rene Villalobos., 2009. Application of planning models in the agri-food supply chain: A review. European Journal of Operational Research, 128(195): 1-20.

[14] Qi Ershi, Zhao Daozheng., 2004. Logistics Engineering, 2ndedition. Chinese Science and Technology Press, Beijing.

[15] Raynaud, 2012. Emmanuel Loic Sauvee and Egizio Valcesch in i. Governance of the Agri-food Chains as a Vector of Credibility for Quality Signalization in Europe. 10th EAAE Congress "Exploring diversity in the European Agri-food System”, Zaragoza, Spain.

[16] Samir K.Srivastava., 2007. Green supply-chain management: a state-ofthe-art literature review.International journal of management reviews, 18(9):53-80.

[17] Terry Marsden, Jo Banks and Gilian Bristow., 2000. Food supply chain approaches: exploring their role in rural development. European society of rural sociology, 58 (10): 424-439.

[18] Wang Wenxing, 2014. Collaborative Information Management in Agricultural Products Supply Chain in China: A Case Study of Wumart, 26th Chinese Control and Decision Conference (CCDC), Changsha.

[19] Yan Bo, Shi Ping.,2014 Risk Assessment and Control of Agricultural Supply Chain on Internet of Things. Journal of Engineering Management, 80(3): 196-204.

[20] Yang Lunbiao,GaoYingyi., 2011. Principle and Application of Fuzzy Mathematics, 5thedition. South China University of Technology Press, Guangzhou. 